\title{
CHANGES IN SEDIMENT ACCUMULATION RATE IN AN OXBOW LAKE FOLLOWING LATE 19TH CENTURY CLEARING OF LAND FOR AGRICULTURAL USE: A ${ }^{210} \mathrm{~Pb},{ }^{137} \mathrm{Cs}$, AND ${ }^{14} \mathrm{C}$ STUDY IN MISSISSIPPI, USA
}

\author{
Gregg R Davidson ${ }^{1,2} \bullet$ Meredith Carnley $^{1} \cdot$ Todd Lange $^{3} \cdot$ Stanley J Galicki ${ }^{4} \bullet$ Andrew Douglas $^{5}$
}

ABSTRACT. Sediment cores were collected from 2 sites in the forested fringe of an oxbow lake surrounded by land that was converted from forest to agricultural use in the late 19th century. The 2 sampling areas were selected to represent areas of high (West site) and low (East site) current sediment accumulation rates, based on distance from a perennially discharging stream. Modern (post settlement and land clearing) sediment accumulation rates were calculated using ${ }^{210} \mathrm{~Pb}$ and ${ }^{137} \mathrm{Cs}$ on bulk sediment samples from 2 cores from each site. Two additional cores were collected from each site for radiocarbon analysis of twig cellulose with the assumption that most twigs in the sediment within the forested fringe fell from overhead and are contemporaneous with the sediment. Only the West site, however, yielded sufficient identifiable twig material for analysis. Modern sediment accumulation rates based on ${ }^{210} \mathrm{~Pb}$ and ${ }^{137} \mathrm{Cs}$ fall between $0.2-0.4 \mathrm{~cm} / \mathrm{yr}$ at the East site, and $0.7-1.3 \mathrm{~cm} / \mathrm{yr}$ at the West site (nearest the stream inlet), with approximate agreement between the ${ }^{210} \mathrm{~Pb}$ and ${ }^{137} \mathrm{Cs}$ methods. Modern sediment accumulation rate based on bomb-pulse ${ }^{14} \mathrm{C}$ activity of twigs from cores from the West site is approximately $1.0 \mathrm{~cm} / \mathrm{yr}$, in agreement with the ${ }^{210} \mathrm{~Pb}$ and ${ }^{137} \mathrm{Cs}$ results. Historic sediment accumulation rates were estimated at the West site using twigs from deeper intervals with pre-bomb ${ }^{14} \mathrm{C}$ activity. Sediment covering approximately $1000 \mathrm{yr}$ of pre-settlement sediment accumulation exhibited evidence of minor bioturbation or in-washing of reworked material, but with a clearly lower accumulation rate of less than $0.1 \mathrm{~cm} / \mathrm{yr}$.

\section{INTRODUCTION}

A common method of assessing erosion within a watershed is to measure the modern rate of sediment accumulation in a reservoir or lake that receives runoff from the area of interest (e.g. Dendy and Boulton 1976; Ritchie et al. 1983; Hai et al. 1999). Using this approach, many studies have documented higher rates of erosion in watersheds within cultivated land than from comparable watersheds containing less cultivated acreage (Ursic and Dendy 1965; Ritchie et al. 1974; Ritchie et al. 1986). In a few studies, changes in the calculated rate of sediment accumulation in a reservoir or lake over a period of several decades has been attributed to changes in agricultural practice (e.g. Ritchie et al. 1986), but little data exists on rates of erosion or sedimentation prior to cultivation within a specific watershed.

An ideal site for quantifying historical lacustrine sediment accumulation rates before and after surrounding land was cleared and cultivated would be a lake meeting the following criteria: (1) a uniform rate of deposition prior to clearing, (2) no scouring or bioturbation of deposited sediment, (3) a several decade history of sediment accumulation following clearing, and (4) the presence of contemporaneous, identifiable, and datable material throughout the sediment profile. These conditions are approximately met in the numerous oxbow lakes on the ancestral floodplain of the lower Mississippi River, where large-scale clearing began just over a century ago.

\footnotetext{
${ }^{1}$ Department of Geology and Geological Engineering, University of Mississippi, Carrier 118, University, Mississippi 38677, USA.

${ }^{2}$ Corresponding author. Email: davidson@olemiss.edu

${ }^{3}$ NSF-Arizona AMS Facility, Department of Physics, University of Arizona, Physics Building, 1118 East Fourth St., P.O. Box 210081, Tucson, Arizona 85721, USA

${ }^{4}$ Geology Department, Millsaps College, 1701 N. State St., Jackson, Mississippi 39210, USA.

${ }^{5}$ Department of Biology, University of Mississippi, University, Mississippi 38677, USA.
} 


\section{STUDY SITE}

Sky Lake is an oxbow lake located $10 \mathrm{~km}$ north of Belzoni, Mississippi, USA (Figure 1). Sky Lake is believed to have been an ancient channel of the Mississippi River abandoned between 7500 and 10,000 BP (Saucier 1994). Personal records from local residents, many of whom are descendants of the original settlers, indicate that clearing of the forests around the lake began in the late 1880s and continued until all usable lands were under tillage by the 1920s (Mark Simmons, personal communication). A seasonally inundated, forested fringe up to $0.8 \mathrm{~km}$ wide still surrounds the lake. The forested fringe is dominated by waterlocust (Gleditsia aquatica), water tupelo (Nyssa aquatica), and large bald cypress trees (Taxodium distichum).

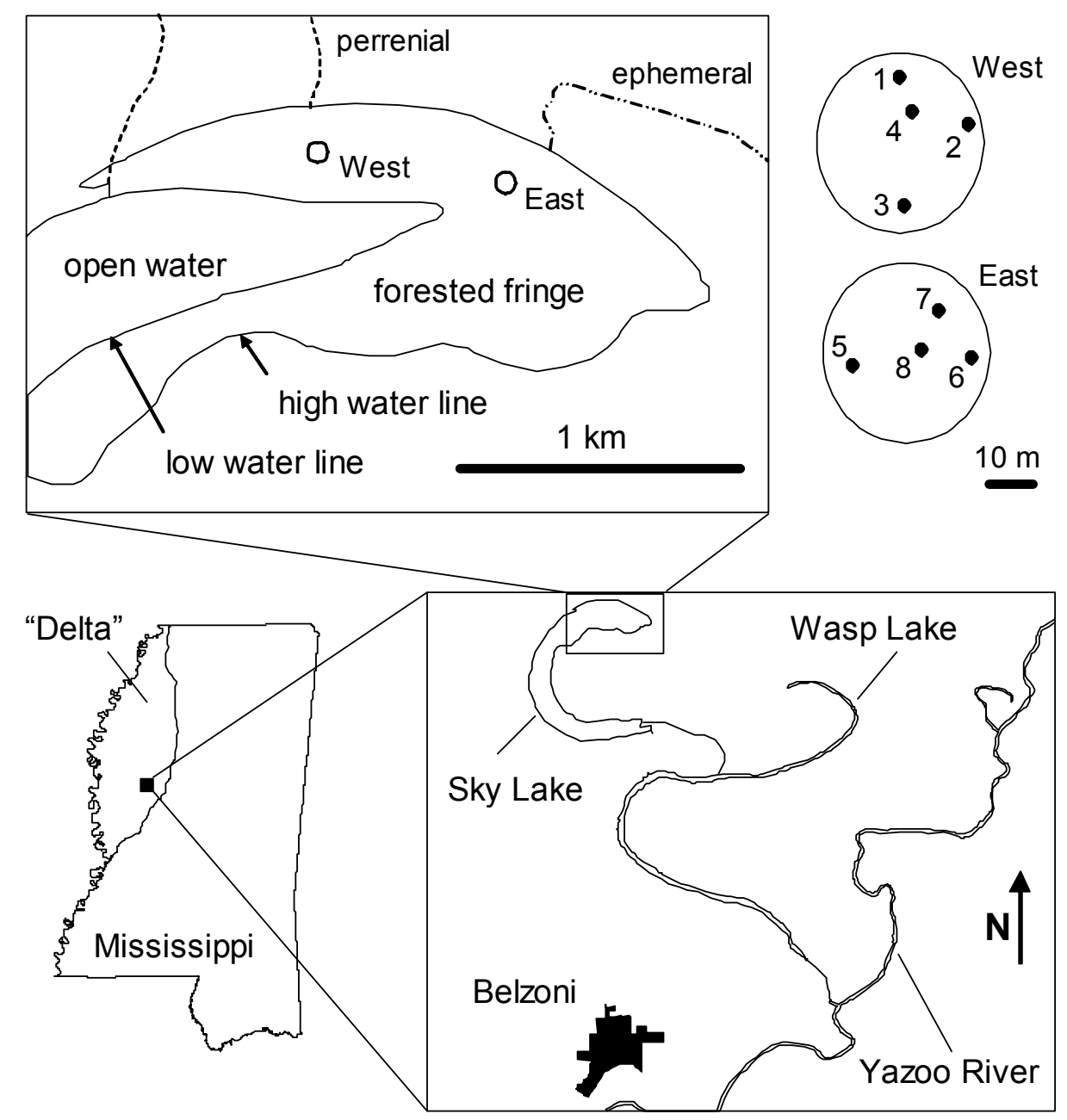

Figure 1 Sky Lake, Humphreys County, Mississippi. The ancestral floodplain of the Mississippi River in the northwestern corner of Mississippi is known as the Delta region. The stream nearest the West sampling site is perennial; the stream nearest the East site is ephemeral. Enlargements of the West and East sites are shown to the right with core numbers identifying the relative location of each core within the sampling site. 
The surface area draining into Sky Lake consists of approximately 1860 ha of agricultural land. Runoff from precipitation and irrigation reaches the lake through diffuse overland flow and through several small, low-energy streams. The flow is normally southward with discharge through Wasp Lake into the Yazoo River. During seasonal flooding, the Yazoo River backflows through Wasp Lake into Sky Lake. Both backflow and stream inflow are low velocity events, resulting in a predominance of clay size particles entering the lake. Historically, Sky Lake could completely drain during prolonged dry periods, but surface outflow is now limited by a flow control structure installed in 1980.

\section{METHODS}

\section{Site Selection}

Two areas within the northern vegetated fringe in Sky Lake were selected based on visual observations of varying sedimentation regimes (Figure 1). The West site is located near the mouth of a lowenergy perennial stream. Water entering the wetland from the stream is typically turbid, and tree litter on the wetland floor is coated with fine grained sediment. The East site is more isolated from perennial stream inlets. Water entering the wetland here following storm events is generally clear and surface tree litter is not coated with sediment. Bark and leaf litter in all sediment cores showed no visible sign of reworking by scour or bioturbation. Redox measurements on sediment cores collected from the same areas by Galicki (2002) indicate that the sediment is oxygen poor during much of the year, which should limit the persistence of burrowing organisms.

\section{Sample Collection}

Four sediment cores were collected from each of the 2 sites. The West site is represented by Cores 1 through 4, and the East site by Cores 5 through 8 (Table 1). Cores 1 and 5 were collected in 1998 for ${ }^{210} \mathrm{~Pb}$ and ${ }^{137} \mathrm{Cs}$ analysis and reported by Galicki (2002). Three additional cores were collected from each site in 2002, two at each site for ${ }^{14} \mathrm{C}$ analysis, and one at each site for additional ${ }^{210} \mathrm{~Pb}$ and ${ }^{137} \mathrm{Cs}$ analyses. Sediment cores were collected by manual insertion of a 10-cm PVC pipe to a depth of up to $2 \mathrm{~m}$. Compaction during coring was tracked by recording the thickness of the sediment core inside the core barrel every $10 \mathrm{~cm}$ of penetration (Morton and White 1995). The core was extruded in the laboratory using a calibrated threaded rod and cut into intervals ranging from 0.9 to $5 \mathrm{~cm}$ thick depending on the estimated deposition rate and intended use (Table 1). Additional compaction during extrusion was insignificant (based on comparison of the length of the core prior to extrusion with the sum of each sectioned interval following extrusion). The outer $0.6 \mathrm{~cm}$ of each wafer was cut away and discarded. Water content was determined by weighing before and after drying at $60{ }^{\circ} \mathrm{C}$.

Table 1 Core information.

\begin{tabular}{lllllr}
\hline Location & Core $^{\mathrm{a}}$ & $\begin{array}{l}\text { Intended } \\
\text { application }\end{array}$ & $\begin{array}{l}\text { Core depth } \\
(\mathrm{cm})\end{array}$ & $\begin{array}{l}\text { Interval thickness } \\
(\mathrm{cm})\end{array}$ & $\mathrm{n}^{\mathrm{c}}$ \\
\hline West site & 1 & ${ }^{210} \mathrm{~Pb},{ }^{137} \mathrm{Cs}$ & 70 & 5.0 & 10 \\
& 2 & ${ }^{210} \mathrm{~Pb},{ }^{137} \mathrm{Cs}$ & 67 & 3.0 & 18 \\
& 3 & ${ }^{14} \mathrm{C}$ & 170 & 2.3 & 31 \\
& 4 & ${ }^{14} \mathrm{C}$ & 186 & 5.3 & 8 \\
East site & 5 & ${ }^{210} \mathrm{~Pb},{ }^{137} \mathrm{Cs}$ & 70 & 3.0 & 7 \\
& 6 & ${ }^{210} \mathrm{~Pb},{ }^{137} \mathrm{Cs}$ & 35 & 0.9 & 8 \\
& 7 & ${ }^{14} \mathrm{C}$ & 85 & 0.9 & 0 \\
\hline
\end{tabular}

${ }^{\mathrm{a}}$ Cores 1 and 5 are upper portion of cores 3 and 4, respectively, in Galicki (2002).

${ }^{\mathrm{b}}$ Corrected for compaction during core collection.

${ }^{\mathrm{c}}$ Number of intervals analyzed for ${ }^{210} \mathrm{~Pb}$ and ${ }^{137} \mathrm{Cs}$, or for ${ }^{14} \mathrm{C}$. 
Sediments typically become more compact with depth, requiring normalization of sediment thickness based on dry bulk density or water content to allow direct comparison of recent and ancient sedimentation rates (Martin and Rice 1981). Compaction at Sky Lake, however, is apparently not significant within the upper $2 \mathrm{~m}$. Water content, dry bulk density, and organic content show no consistent trend with depth (Galicki 2002), and normalization was not required.

\section{${ }^{210} \mathrm{~Pb}$ and ${ }^{137} \mathrm{Cs}$ Analysis}

${ }^{210} \mathrm{~Pb}$ and ${ }^{137} \mathrm{Cs}$ activities were determined at the University of South Carolina on powdered, bulk sediment samples using a low-energy planar germanium detector calibrated using NIST soil samples (Dukat and Kuehl 1995). The supported level of ${ }^{210} \mathrm{~Pb}$ was determined by monitoring the level of ${ }^{226} \mathrm{Ra}$ gamma peaks. Corrections were made for self-absorption of low-energy gamma rays (Cutshall et al. 1983). Sedimentation rates based on ${ }^{210} \mathrm{~Pb}$ assumed a constant rate of sediment accumulation and rate of atmospheric ${ }^{210} \mathrm{~Pb}$ fallout.

\section{${ }^{14} \mathrm{C}$ Analysis}

Samples from the cores for ${ }^{14} \mathrm{C}$ analysis were separated into 3 fractions: (1) large organic material retained on a 710- $\mu \mathrm{m}$ sieve (\#25), (2) fine, mostly organic debris retained on a $250-\mu \mathrm{m}$ sieve (\#60), and (3) a predominantly clay fraction that passed through the $250-\mu \mathrm{m}$ sieve. A binocular microscope was used to identify woody plant stems (twigs), representing 1 to $2 \mathrm{yr}$ of growth, from the largest fraction. Wood fragments derived from larger branches or tree trunks were selected from several depths for comparison purposes.

Tree-ring samples were collected from a single 1.3-cm-diameter core taken from a 100-yr-old bald cypress tree growing in the vicinity of sediment core collection. The tree rings were dated by crosscorrelation with cores taken from over 70 different trees in the same wetland. Individual annual rings were separated using a stainless steel razor blade and stored dry prior to chemical pretreatment.

Woody material was pretreated using an AAA-bleach procedure for removing potential contaminants and extraction of holo-cellulose (adapted from Hoper et al. 1998). Intact samples (all $<3 \mathrm{~mm}$ in diameter) were placed sequentially in $1 \mathrm{M} \mathrm{HCl}$ for $2 \mathrm{hr}$ at $60^{\circ} \mathrm{C} ; 0.5 \mathrm{M} \mathrm{NaOH}$ at $60{ }^{\circ} \mathrm{C}$ for $1 \mathrm{hr}$ (repeated until solution was clear); $1 \mathrm{M} \mathrm{HCl}$ for $1 \mathrm{hr}$ at $60^{\circ} \mathrm{C}$; and a bleaching solution of $0.3 \mathrm{M}$ $\mathrm{NaClO}_{2}$ and $0.07 \mathrm{M} \mathrm{HCl}$ at $60{ }^{\circ} \mathrm{C}$ until the material turned white (typically 4-8 hr). Samples were rinsed with distilled water between each step. A few very small samples received shortened wash times to prevent complete dissociation and are identified in the discussion of results and figures.

Organic debris samples collected on the $250-\mu \mathrm{m}$ sieve were consistently lost when applying the full AAA pretreatment (without the bleach solution). Necessity of the pretreatment for this fraction was tested on split samples from three depths from Core 3. A split from each depth was pretreated as above but with only $1 \mathrm{hr}$ in each solution and a single $\mathrm{NaOH}$ wash. The second split was untreated. The ${ }^{14} \mathrm{C}$ activities of untreated and pretreated material differed by less than $1 \%$. The remaining intervals were analyzed without pretreatment.

Prepared samples were combusted in Vicor ${ }^{\circledR}$ or quartz tubing with excess $\mathrm{CuO}$ over an open propane flame. Evolved gases were passed through hot $\mathrm{Cu}$ and $\mathrm{Ag}$ wire to convert nitrogen oxide gases to $\mathrm{N}_{2}$ and to remove residual halides. $\mathrm{CO}_{2}$ was purified cryogenically and split into fractions for $\delta^{13} \mathrm{C}$ and ${ }^{14} \mathrm{C}$ analyses. Graphite targets for ${ }^{14} \mathrm{C}$ analysis were prepared by conversion of $\mathrm{CO}_{2}$ to graphite in the presence of powdered $\mathrm{Zn}$ and $\mathrm{Fe}$, and analyzed by accelerator mass spectrometry (AMS) at the NSF-Arizona AMS facility. Calibrated ages for pre-bomb samples were determined using CALIB 4.4 (Stuiver et al. 1993; revision 4.4: http://radiocarbon.pa.qub.ac.uk/calib/). 


\section{RESULTS AND DISCUSSION}

\section{${ }^{210} \mathrm{~Pb}$ and ${ }^{137} \mathrm{Cs}$ Results}

Sediment accumulation rates since clearing of the land around Sky Lake were calculated for 2 cores from each site using ${ }^{210} \mathrm{~Pb}$ and ${ }^{137} \mathrm{Cs}$ activities (Figure 2). Agreement between cores and methods in the East site was relatively good. The ${ }^{137} \mathrm{Cs}$-based sediment accumulation rates calculated from Cores 5 and 6 overlap at approximately $0.3 \mathrm{~cm} / \mathrm{yr}$. Variability in the magnitude of each range given in Figure 2a is a reflection of the uncertainty in the exact location of the ${ }^{137} \mathrm{Cs}$ peak within the 3- or 5 -cm interval analyzed. The same cores yield ${ }^{210} \mathrm{~Pb}$-based sediment accumulation rates of 0.37 and $0.23 \mathrm{~cm} / \mathrm{yr}$, respectively (Figure $2 \mathrm{~b}$ ).

Post land-clearing sediment accumulation rates calculated for the West site are approximately 3 times higher than for the East site. The ${ }^{137} \mathrm{Cs}$-based sediment accumulation rates from Cores 1 and 2 overlap at approximately $0.9 \mathrm{~cm} / \mathrm{yr}$, with a ${ }^{210} \mathrm{~Pb}$-based rate of $1.0 \mathrm{~cm} / \mathrm{yr}$ for Core 2 , and a slightly higher rate of $1.3 \mathrm{~cm} / \mathrm{yr}$ for Core 1 . Deviations from linearity on the ${ }^{210} \mathrm{~Pb}$ plots suggest that some bioturbation or variation in sediment influx has occurred, but a clear trend in the excess (unsupported) ${ }^{210} \mathrm{~Pb}$ is evident to depths of approximately $55 \mathrm{~cm}$ in cores from the West site, and $30 \mathrm{~cm}$ in cores from the East site. The depth of datable sediment represents the last 50 to $100 \mathrm{yr}$ of deposition.

Sediment accumulation rate calculations using ${ }^{137} \mathrm{Cs}$ are based on the assumption that peak ${ }^{137} \mathrm{Cs}$ fallout occurred in 1964 following the heaviest period of atmospheric testing of nuclear weapons (Perkins and Thomas 1980), a constant sediment accumulation rate in the ensuing years, and no post-depositional migration of Cs (e.g. Krishnaswamy et al. 1971; Goodsite et al. 2001). The sharp ${ }^{137} \mathrm{Cs}$ peaks in 3 of the 4 cores (Cores 2, 5, and 6) and relative agreement with the ${ }^{210} \mathrm{~Pb}$-based rates suggests that Cs migration has not been significant at these locations since deposition (Figure 2a). The more diffuse peak in Core 1 might result from localized migration of Cs, from dilution of the peak ${ }^{137} \mathrm{Cs}$ activity by under or overlying sediment in the large $(5 \mathrm{~cm})$ sample interval, or from minor bioturbation. The ${ }^{210} \mathrm{~Pb}$ activity from Core 1 (Figure $2 \mathrm{~b}$ ), however, shows minimal evidence of reworking.

The modern sediment accumulation rates calculated for Sky Lake are significantly lower at both sites than reported in an earlier study of adjacent Wasp Lake. Ritchie et al. (1979) reported sedimentation rates based on ${ }^{137} \mathrm{Cs}$ measurements that ranged from 2.5 to $7.7 \mathrm{~cm} / \mathrm{yr}$ in Wasp Lake. Higher sediment accumulation rates may be caused by closer proximity to the Yazoo River (Figure 1). It is also possible that sediment discharge to these lakes has decreased in the last $25 \mathrm{yr}$, though no slope change is evident in the ${ }^{210} \mathrm{~Pb}$ plots from Figure $2 \mathrm{~b}$.

\section{${ }^{14} \mathrm{C}$ Results}

Small branches in lake sediments typically represent material that was washed into the lake after some residence time on the terrestrial forest floor. When dating ancient sediments, a delay of a few years does not represent a significant error (Björck and Wohlfarth 2001), but the error may be more significant when dating modern sediments utilizing bomb pulse activities. In forested wetlands, however, twigs are likely to be buried soon after they fall and should yield a ${ }^{14} \mathrm{C}$ age that is nearly contemporaneous with the date of deposition. Leaf stems detach annually from bald cypress and deciduous wetland trees, and a large percentage of small branches (representing 1 to 2 yr of growth) are shed within the same year of death. Tests of 10 sample sets from different depths demonstrated that the ${ }^{14} \mathrm{C}$ activity of twig samples was consistently higher than the activity of undefined wood fragments (from decomposed tree trunks or larger branches) and the activity of miscellaneous organic debris collected on a $250-\mu \mathrm{m}$ sieve (Figure 3). 
(a)
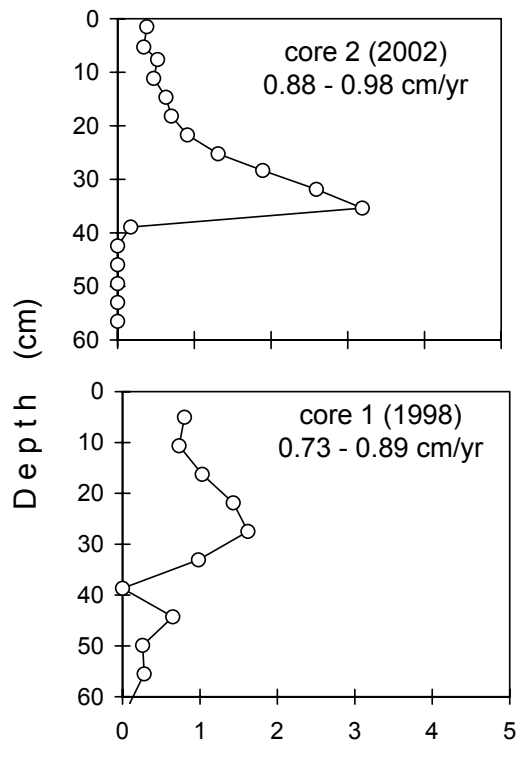

${ }^{137} \mathrm{Cs} \quad(\mathrm{dpm} / \mathrm{g})$
East
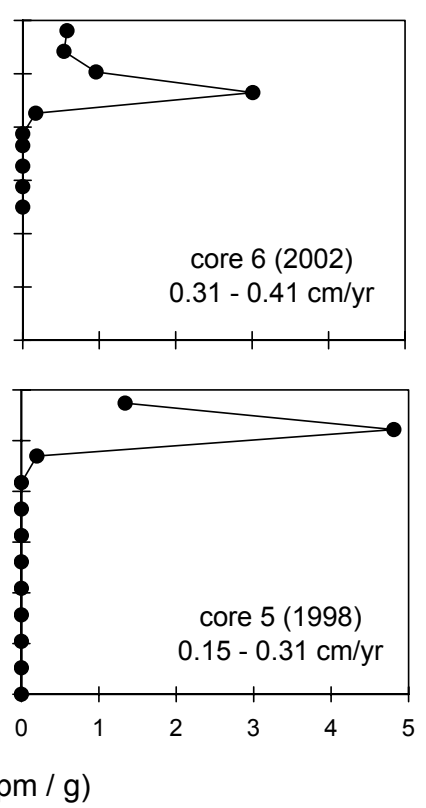

East

(b)

West
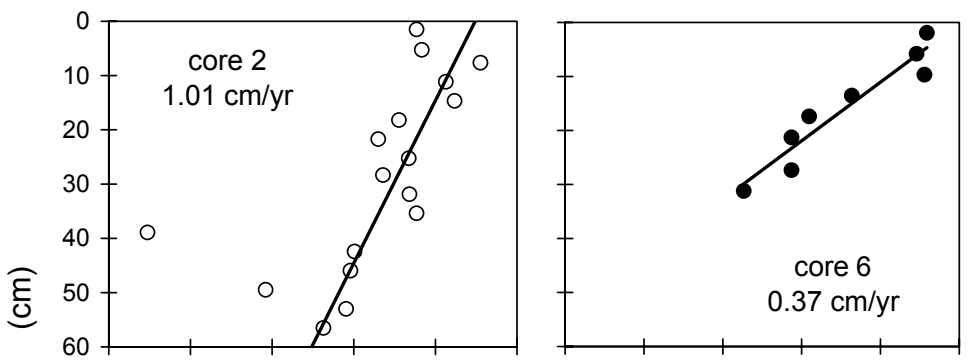

둥

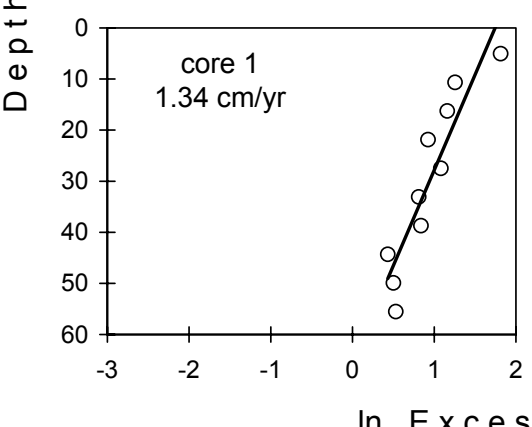

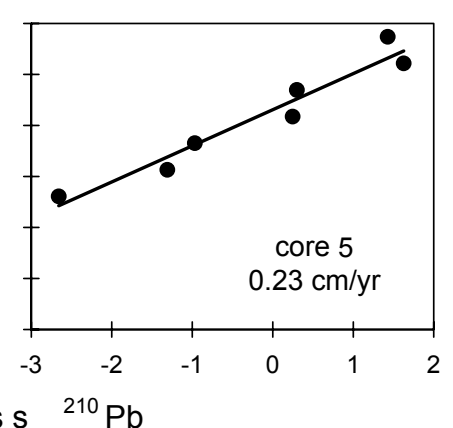

Figure 2 (a) ${ }^{137} \mathrm{Cs}$ activity and (b) $\ln$ excess ${ }^{210} \mathrm{~Pb}$ activity in sediment samples with depth. The dates given in (a) refer to the year the cores were collected. Data for Cores 1 and 5 are from Galicki (2002). The thickness of each sample interval was $5 \mathrm{~cm}$ for Cores 1 and 5, and $3 \mathrm{~cm}$ for Cores 2 and 6 (Table 1). 


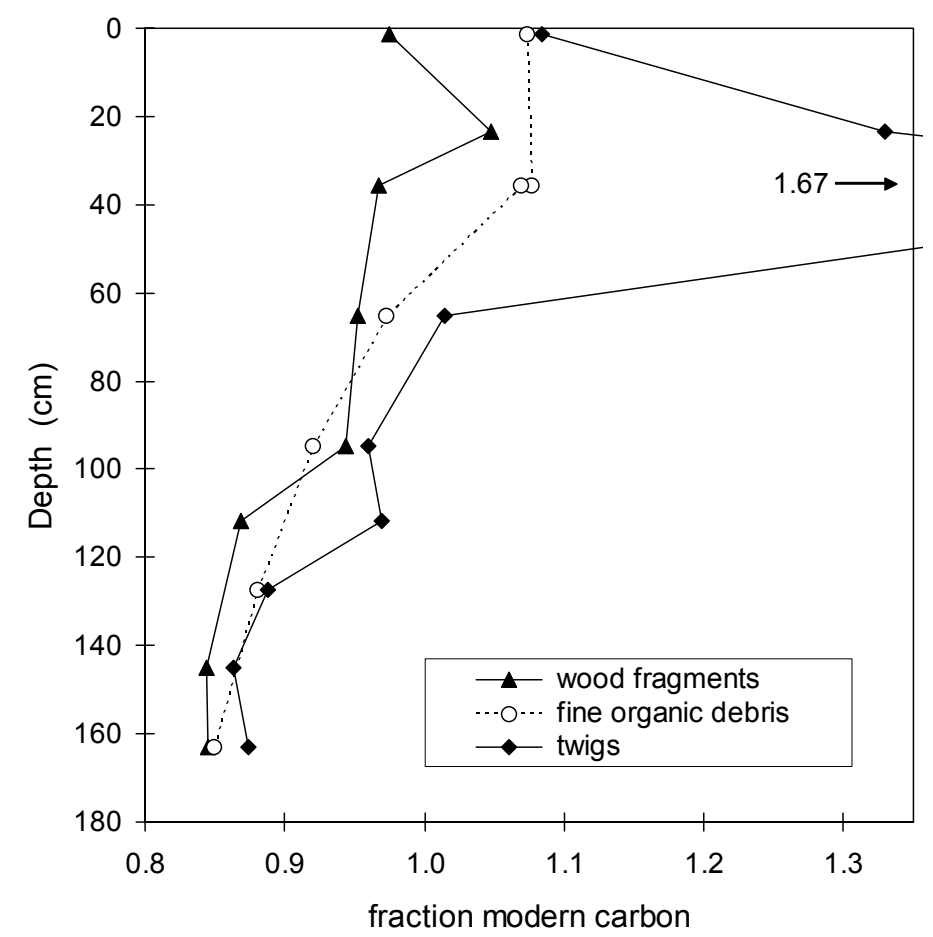

Figure $3{ }^{14} \mathrm{C}$ activity of wood fragments, fine organic debris $(710-250 \mu \mathrm{m})$, and twig samples from the same depths from Core 3 (West site). Analytical uncertainty for ${ }^{14} \mathrm{C}$ activity $(1 \sigma)$ is equal to or smaller than the size of the data markers.

Post land-clearing sediment accumulation rates were determined for Cores 3 and 4 in the West site using bomb-pulse ${ }^{14} \mathrm{C}$ activity of twig cellulose. The bald cypress tree-ring activity for the years 1950-2000 was aligned with the post-bomb sediment data to achieve the best fit (Figure 4). The tree-ring activity curve shown in Figure 4 is consistent with the annualized atmospheric ${ }^{14} \mathrm{C}$ activities reported by Goodsite et al. (2001) for the Northern Hemisphere (mid to high latitudes). The 2 sediment cores were sectioned into intervals of equivalent thickness, but a much higher number of intervals from Core 3 were analyzed for ${ }^{14} \mathrm{C}$ (Table 1).

Of the 17 sediment samples from the 2 cores with post-bomb ${ }^{14} \mathrm{C}$ activity ( 13 from Core 3 and 4 from Core 4), 13 align well with the atmospheric ${ }^{14} \mathrm{C}$ curve represented by the tree-ring data, with a clearly identifiable maximum during 1963-1964 (Figure 4). The 4 points that fall significantly off the curve, all from Core 3, may represent evidence of minor bioturbation, introduction of reworked material, or a long delay between death of a twig and separation from the tree. Based on the general fit to the atmospheric bomb-pulse, the ${ }^{14} \mathrm{C}$ profile indicates a sediment accumulation rate of $1.0 \mathrm{~cm} / \mathrm{yr}$, and is consistent with the ${ }^{210} \mathrm{~Pb}$ and ${ }^{137} \mathrm{Cs}$ results for samples reflecting the last $50 \mathrm{yr}$ of sedimentation at the West site.

The pre-bomb data shows a generally decreasing trend with depth, but the data does not fall neatly along a linear depth versus calibrated age curve (Figure 5). Variability may be due to an occasional influx of reworked material from the surrounding forest (present until the last century) or due to bioturbation, though the data from Figure 3 suggests that the sediment is not highly mixed. Thorough mixing should result in a more random relationship between the ${ }^{14} \mathrm{C}$ activity of wood fragments, fine organic debris, and twigs. The generally intermediate activity of organic debris shown in Figure 3 is 


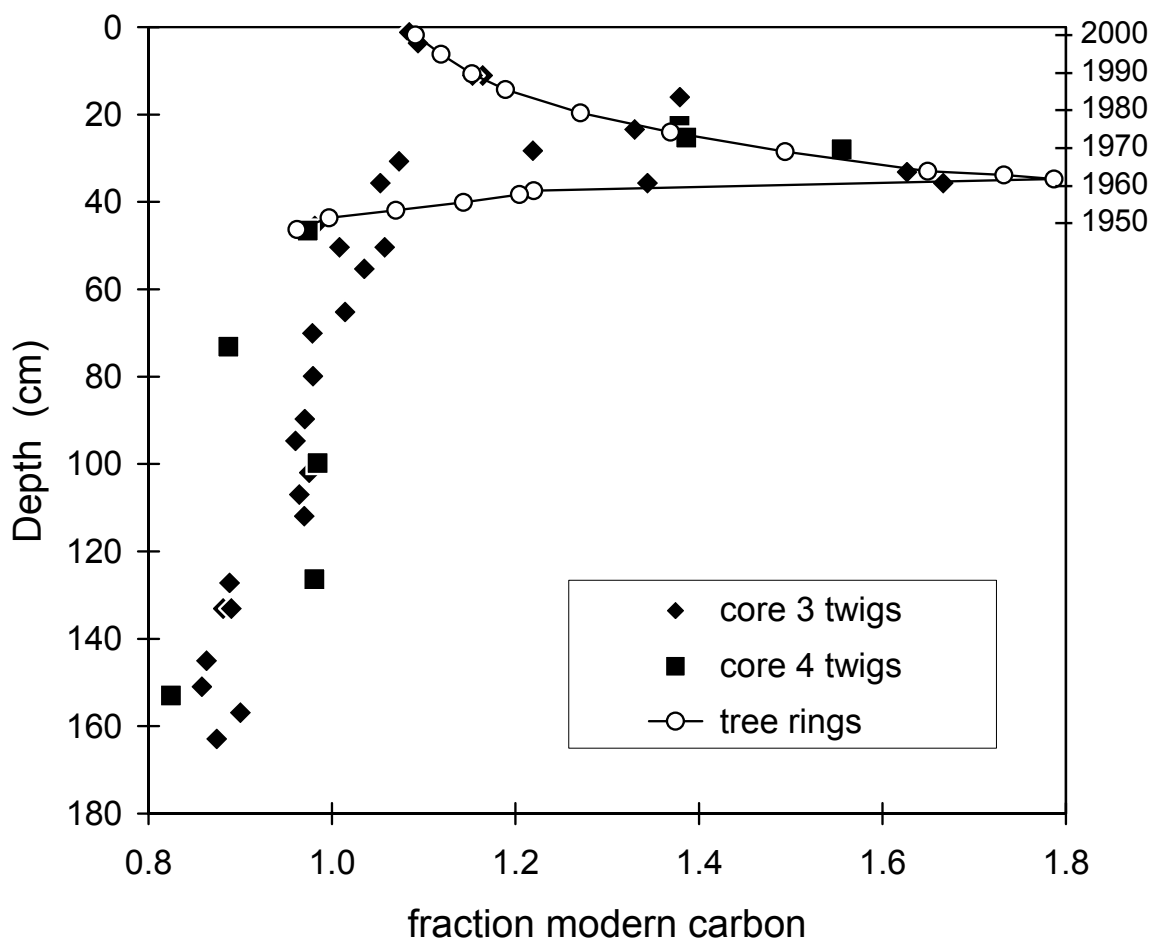

$\stackrel{\oplus}{\frac{1}{\pi}}$

Figure $4{ }^{14} \mathrm{C}$ activity of twig samples collected from Cores 3 and 4 from the West site, and of individual tree rings collected from a bald cypress tree growing nearby. The calendar year of tree-ring growth is shown on the right axis and aligned with the peak activity observed in the sediment samples. Analytical uncertainty $(1 \sigma)$ is equal to or smaller than the size of the data markers.

more consistent with in-place decomposition of older wood and younger twigs, plants, and insect remains resulting in finer organic debris of mixed activity.

In spite of the variability in the pre-bomb data, it is clear that the average pre-settlement sedimentation rate was much less than the current rate (Figure 5). A best-fit line through the data below $60 \mathrm{~cm}$, using the median points of dates assigned the highest probability, yields an average sedimentation rate of $0.07 \mathrm{~cm} / \mathrm{yr}$ for the $1000 \mathrm{yr}$ preceding clearing. Indeed, even a highly biased line through the data favoring higher sedimentation rates does not exceed $0.1 \mathrm{~cm} / \mathrm{yr}$.

Twig samples proved to be much more difficult to find in cores collected from the East site. Twigs from these cores were smaller and harder to differentiate from small roots. The small size also precluded thorough pretreatment, further increasing the uncertainty associated with the results. (No recoverable sample remained after full AAA-bleach pretreatment.) Analyzed samples were pretreated for shorter time periods in each solution, typically no more than $1 \mathrm{hr}$. Nearly all samples from Core 7 yielded post-bomb ${ }^{14} \mathrm{C}$ activities with no discernible pattern, possibly reflecting accidental selection of small roots instead of twigs. Identifiable twig material was equally difficult to find in Core 8 and no ${ }^{14} \mathrm{C}$ analyses were performed. The relative scarcity of identifiable twig material at this site is probably due to the fact that the leaf and branch litter is not coated as quickly with clay. The organic debris is more aerated and decomposition should be more rapid. However, measurements of organic carbon (based on loss on ignition) did not show a significant difference in the total organic content in sediment cores from the 2 sites (Galicki 2002). 


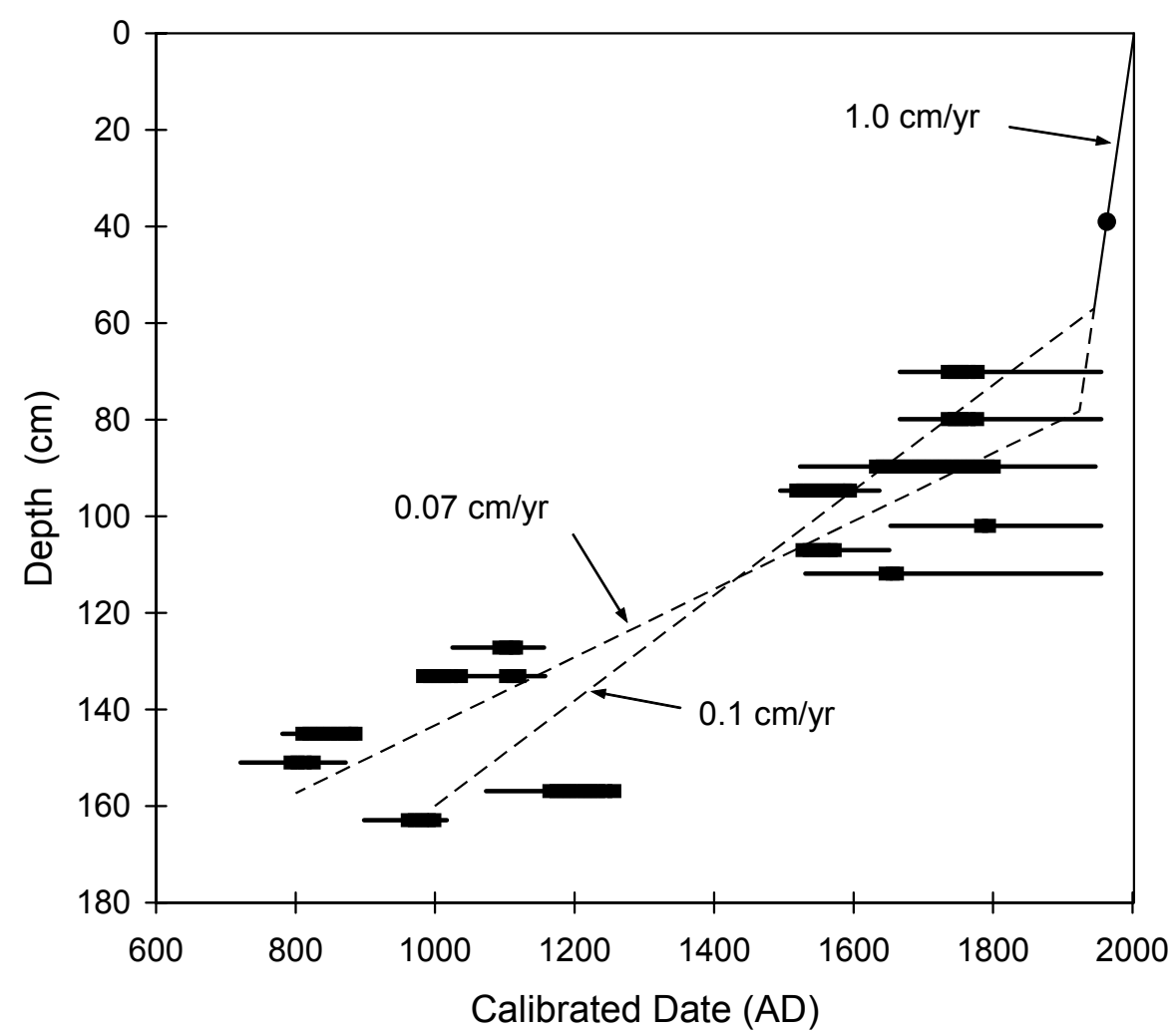

Figure 5 Calibrated dates for pre-bomb twigs in sediment from Core 3 only (West site) versus depth. The single filled circle marks the depth of the peak atmospheric ${ }^{14} \mathrm{C}$ activity observed in the tree rings and sediment in Figure 4, and corresponds to a sediment accumulation rate of $1.0 \mathrm{~cm} / \mathrm{yr}$ (the remaining post-bomb data are not plotted). The horizontal lines represent the range of possible dates $(1 \sigma)$ for the pre-bomb samples, with the range of highest probability shown as a thicker line. A linear regression through the highest probability ranges yields a line with a slope of $0.07 \mathrm{~cm} / \mathrm{yr}$. A line representing an arbitrary sediment accumulation rate of $0.1 \mathrm{~cm} / \mathrm{yr}$ is plotted for comparison.

\section{CONCLUSIONS AND SUMMARY}

Sediment accumulation rates were determined for multiple sediment cores collected from two different locations at Sky Lake in northwestern Mississippi. Estimates using ${ }^{210} \mathrm{~Pb}$ and ${ }^{137} \mathrm{Cs}$ activities measured in bulk sediment and ${ }^{14} \mathrm{C}$ activity in twig cellulose gave comparable results of approximately $1.0 \mathrm{~cm} / \mathrm{yr}$ at the West site (near stream inlet) during the last 50 to $100 \mathrm{yr}$. The sedimentation rate prior to clearing the land for agriculture was an order of magnitude less based on ${ }^{14} \mathrm{C}$ activities alone. Erosion rates from the surrounding fields should be proportional to the rate of sediment accumulation in the lake, which means it is likely that erosional losses around Sky Lake were also an order of magnitude less when the surrounding land was still forested. At the East site, more isolated from perennial stream inlets, comparisons were only possible using ${ }^{210} \mathrm{~Pb}$ and ${ }^{137} \mathrm{Cs}$. The 2 methods gave comparable results for modern sediment accumulation rates of approximately $0.2-0.4 \mathrm{~cm} / \mathrm{yr}$. Estimates using ${ }^{14} \mathrm{C}$ activity may still be possible using either more sediment from each depth, or by selecting different material for dating. 


\section{ACKNOWLEDGEMENTS}

Thanks to Jared Holland and John Hart for assistance with sample processing and $\delta^{13} \mathrm{C}$ analysis, and to the NSF-Arizona AMS laboratory for advise and ${ }^{14} \mathrm{C}$ analyses. Partial funding for this work was obtained from the USDA-ARS National Sedimentation Laboratory, Oxford, Mississippi.

\section{REFERENCES}

Björck S, Wohlfarth B. 2001. ${ }^{14} \mathrm{C}$ chronostratigraphic techniques in paleolimnology. In: Last WM, Smol JP, editors. Tracking Environmental Change Using Lake Sediments. Volume 1: Basin Analysis, Coring, and Chronological Techniques. Dordrecht, the Netherlands: Kluwer Academic Publishers. p 205-45.

Cutshall NH, Larson IL, Olsen CR. 1983. Direct analysis of ${ }^{210} \mathrm{~Pb}$ in sediment samples: self absorption correction. Nuclear Instruments and Methods in Physics Research B 206:309-17.

Dendy FE, Boulton GC. 1976. Sediment yield-runoffdrainage area relationships in the United States. Journal of Soil and Water Conservation 31:264-6.

Dukat DA, Kuehl SA. 1995. Non-steady-state ${ }^{210} \mathrm{~Pb}$ flux and the use of ${ }^{228} \mathrm{Ra} /{ }^{226} \mathrm{Ra}$ as a geochronometer on the Amazon continental shelf. Marine Geology 125:32950.

Galicki SJ. 2002. Bald cypress dendrochemistry and sediment geochemistry in a lake fringe wetland, Sky Lake, Mississippi [PhD dissertation]. Oxford: University of Mississippi, USA. 190 p.

Goodsite ME, Rom W, Heinemeier J, Lange T, Ooi S, Appleby PG, Shotyk W, van der Knaap WO, Lohse C, Hansen TS. 2001. High-resolution AMS ${ }^{14} \mathrm{C}$ dating of post-bomb peat archives of atmospheric pollutants. Radiocarbon 43(2B):495-515.

Hai PS, Son PN, Dien NN, Tan VH, Hien PD. 1999. Assessment of erosion and accretion in catchment areas based on ${ }^{210} \mathrm{~Pb}$ and ${ }^{137} \mathrm{Cs}$ contents in soil and sediment. In: Stevenson NR, editor. Isotope Production and Applications in the 21st Century. Proceedings of the 3rd International Conference on Isotopes, Vancouver, Canada, 6-10 September 1999. World Scientific, New Jersey. p 415-8.

Hoper ST, McCormac FG, Hogg AG, Higham TFG, Head MJ. 1998. Evaluation of wood pretreatments on oak and cedar. Radiocarbon 40(1):45-50.

Krishnaswamy S, Lal D, Martin JM, Meybeck M. 1971. Geochronology of lake sediments. Earth and Plane- tary Science Letters 11:407-14.

Martin EA, Rice CA. 1981. Sampling and analyzing sediment cores for ${ }^{210} \mathrm{~Pb}$ geochronology. United States Geological Survey, Open-File Report 81-983.

Morton RA, White WA. 1995. Characteristics of and corrections for core shortening in unconsolidated sediments. Journal of Coastal Research 13:761-9.

Perkins RW, Thomas CW. 1980. Worldwide fallout. In: Hansen WC, editor. Transuranic Elements in the Environment. Springfield, Virginia, USA: Technical Information Center. p 53-82.

Ritchie JC, Cooper CM, McHenry JR. 1979. Recent accumulation of sediment in lakes in the Bear Creek watershed in the Mississippi Delta. Southern Geologist 20:173-80.

Ritchie JC, Cooper CM, McHenry JR. 1986. Sediment accumulation rates in lakes and reservoirs in the Mississippi River Valley. In: Wang SY, editor. Third International Symposium on River Sedimentation, The University of Mississippi, 31 March-4 April 1986. p 1357-65.

Ritchie JC, Cooper CM, McHenry JR, Schiebe FR. 1983. Sediment accumulation in Lake Chicot, Arkansas. Environmental Geology 5:79-82.

Ritchie JC, McHenry JR, Gill AC. 1974. Fallout ${ }^{137}$ Cs in the soils and sediments of three small watersheds. Ecology 55:887-90.

Saucier RT. 1994. Geomorphology and Quaternary geologic history of the lower Mississippi valley. United States Army Corps of Engineers, Vicksburg, Vol. II.

Stuiver M, Reimer PJ. 1993. Extended ${ }^{14} \mathrm{C}$ data base and revised CALIB $3.0{ }^{14} \mathrm{C}$ age calibration program. $R a-$ diocarbon 35(1):215-30. Revision 4.4: http://radiocarbon.pa.qub.ac.uk/calib/.

Ursic SJ, Dendy FE. 1965. Sediment yields from small watersheds under various land uses and forest covers. U.S. Department of Agriculture, Miscellaneous Publication 970. p 47-52. 